\title{
Clinically significant changes in burden and depression among dementia caregivers following nursing home admission
}

\author{
Joseph E Gaugler ${ }^{1 *}$, Mary S Mittelman², Kenneth Hepburn³ ${ }^{3}$ Robert Newcomer ${ }^{4}$
}

\begin{abstract}
Background: Although extensive research exists on informal long-term care, little work has examined the clinical significance of transitions in family caregiving due to a lack of established clinical cut-points on key measures. The objectives of this study were to determine whether clinically significant changes in symptoms of burden and depression occur among caregivers within 12 months of nursing home admission (NHA) of their relatives with dementia, and to identify key predictors of clinically persistent burden and depression in the first year after institutionalization.
\end{abstract}

Methods: Secondary longitudinal analysis of dementia caregivers were recruited from eight catchment areas in the United States with 6- and 12-month post-placement follow-up data. The sample included data on 1,610 dementia caregivers with pre- and six-month post-placement data and 1,116 with pre-placement, six-month, and 12-month post-placement data. Burden was measured with a modified version of the Zarit Burden Inventory. Depressive symptoms were assessed with the Geriatric Depression Scale.

Results: Chi-square analyses found significant $(P<.05)$ reductions in the number of caregivers who reported clinically significant burden and depressive symptoms after NHA compared to pre-placement. Logistic regression models revealed that wives and daughters were most likely to experience clinically persistent burden and husbands were most likely to experience clinically significant depression after NHA.

Conclusions: In addition to suggesting that clinically significant decreases in caregiver burden and depression are likely to occur following institutionalization, the results reveal particular subsets of caregivers who are at continued risk of distress. Such findings can facilitate development of screening processes to identify families at-risk following institutionalization.

\section{Background}

Over 50 million individuals provide unpaid care to adults who are disabled or ill http://www.caregiver.org. The prominence of informal care in the U.S. has led to a large number of studies describing family caregivers [1], examining stress in family caregiving [2,3], and evaluating the effectiveness of psychosocial interventions and respite services for caregiving families [4-6]. As chronic illnesses such as Alzheimer's disease or other dementias progress, critical health transitions (diagnosis, institutionalization, bereavement) may exacerbate

\footnotetext{
* Correspondence: gaug0015@umn.edu

'School of Nursing, Center on Aging, University of Minnesota, Minneapolis, MN, USA Full list of author information is available at the end of the article
}

negative health outcomes for persons with dementia or their family caregivers. Nursing home admission (NHA) in particular is a transition that is considered a key clinical marker of dementia progression [7].

Although extensive research exists on informal longterm care, little work has examined the clinical significance of transitions or other phenomena due to a lack of established clinical cut-points on key caregiving measures [8]. This has made it difficult to interpret results or effects of interventions for dementia caregivers. The high prevalence of dementia among nursing home residents $(69 \%$ of all nursing home residents suffer from some form of cognitive impairment) [9] may place ongoing care demands onto family members. Several studies have noted that families continue to provide
C Biomed Central 
various types of informal (that is, unpaid) assistance to relatives in nursing homes (NHs). Such assistance ranges from visits, to care provision, to staff interaction [10-12]. For these reasons, it would be valuable to determine whether NHA has a clinically significant impact on caregiving outcomes and to identify those variables that predict clinically significant levels of burden and depression among caregivers after NHA. Using a large, multiregional, and longitudinal data set of dementia family caregivers, the present study sought to: 1) determine whether clinically significant reports of burden or depressive symptoms change within 12 months of NHA, and 2) identify factors prior to NHA that predict clinically persistent burden and depression within the first year following institutionalization. These insights will serve to guide the development of effective intervention strategies that offer psychosocial support to dementia caregivers grappling with the potential challenges of NHA.

\section{Caregiving and institutionalization}

Systematic reviews have noted that caregiving burden (or feelings of being overwhelmed with various facets of care), emotional fatigue, and perceptions of entrapment in the caregiving role are at least as important as care recipients' functional and cognitive decline in predicting risk of NH entry [13]. Longitudinal analyses of dementia caregiving make clear that caregiving does not "end" with the institutionalization of a cognitively impaired elderly relative [14]. Instead, family members remained engaged in the lives of institutionalized relatives. While the provision of "hands-on" technical care such as ambulation and transferring are often assumed by direct care workers in the NH setting, family involvement continues and ranges from regular visits, to ongoing provision of more instrumental forms of direct care (such as transportation and financial management), to interaction with staff to ensure proper care is delivered [12,15-18]. Some studies have found that various measures of caregiving stress or depressive symptoms remain stable, or in some cases, increase with NHA [19-23]. Contradictory findings from other studies suggest that institutionalization may result in decreased stress or depressive symptoms following $\mathrm{NH}$ placement as well as improved physical health for caregivers (for example, somatic symptoms, biomarkers of cardiovascular health) [20,24-27]. Some reasons for these discrepant findings include the fairly small samples included in prior research studies, which may have limited the statistical power necessary to detect significant changes in key caregiving outcomes across the NH transition. Similarly, variation in when caregivers are assessed prior to and after NHA (that is, length of follow-up) may have also obscured both the short- and long-term implications of institutionalization on dementia caregivers' stress, depressive symptoms, or other dependent variables.

Studies of dementia caregiving have identified several predictors of depressive symptoms and burden following institutionalization. Behavior problems of care recipients prior to or at the time of NHA appear to predict greater caregiver burden and reduced family involvement following $\mathrm{NH}$ placement (for example, visits, care provision) $[22,28,29]$. Spouse caregivers appear more likely to report greater burden, depressive symptoms, and dissatisfaction after NHA than adult child or other caregivers $[21,30]$. Wives in particular tend to invest greater emotional resources in their roles as "caregivers," and thus may be less willing to relinquish day-to-day care responsibility to a $\mathrm{NH}$ and are more involved in care delivery and supervision when compared to other types of caregivers $[2,12,31,32]$. Family caregivers' lack of satisfaction with help received from others [21,33], the increased functional or cognitive impairment of the relative $[33,34]$, and less involvement with the relative following NHA [34] also appear to be associated with greater distress in caregivers after institutionalization.

\section{Research focus}

Most caregiving research has failed to identify the clinical significance of reported results [8]. Many measures of caregiver stress or well-being do not have established cut-points signifying the presence of clinically relevant symptoms. This has made it difficult to interpret empirical associations between predictor variables and outcomes or determine whether an intervention has had a clinically meaningful effect. The present study advances current research on dementia caregiving and NHA in two ways. First, we developed clinically significant cutpoints and analyzed data on the prevalence of clinically significant burden and depression prior to and up to 6and 12-months post-placement. This initial analysis made it possible to estimate the proportion of caregivers who experienced clinically significant burden and depression in the months following NHA. Given the size of the sample and the amount of longitudinal, postplacement data available, this study aimed to reconcile conflicting results on changes in key caregiving outcomes prior to and following NHA. The second objective was to determine what pre-placement factors predicted clinically persistent burden and depressive symptoms among caregivers up to one year following institutionalization. Variables considered in the predictive analysis included those shown in previous studies to predict NHA in dementia and indicators derived from post-placement analyses of caregiver depression and stress $[21,22,28,29,33,34]$. Per other conceptualizations of stress in dementia caregiving [35], pre-placement burden was considered a predictor of post-placement 
depressive symptoms, as emotional appraisals of dementia care demands (that is, burden) are postulated to influence more global psychological outcomes (that is, depression). Since it is considered a global outcome of dementia caregiving, pre-placement depressive symptoms were not considered as a predictor of post-placement burden in subsequent analyses.

This study extends our previous research examining changes in caregiver burden and depressive symptoms after institutionalization. In a prior study [31] we used the full 6- and 12-month post-placement cohorts of the data set reported here to examine trajectories of change in burden in depressive symptoms prior to and up to one year after NHA. This previous work noted that the amount of change prior to and after institutionalization appeared to drop below clinical thresholds of burden 6and 12-months following NHA. These intriguing initial findings led to the analyses reported in this study, which is a comprehensive, more focused analysis of clinically relevant change in burden and depressive symptoms after the $\mathrm{NH}$ transition. More specifically, this study identifies those factors that resulted in clinically persistent levels of burden and depression prior to and up to one year following NHA when compared to those who fell below these clinical thresholds (thus resulting in a more interpretable comparison). For these reasons the current study builds on our prior work and serves as an independent, notable contribution to understanding how families adapt emotionally and psychologically to NHA. Specifically, understanding factors that are linked to ongoing and clinically relevant burden and depressive symptoms during institutionalization could help social workers, nursing staff (for example, directors of nursing, registered nurses, certified nurse assistants), and medical directors to identify caregivers who are in need of support during $\mathrm{NH}$ entry, thus helping to facilitate families' adaptations to a relative's institutionalization.

\section{Methods}

\section{The Medicare Alzheimer's Disease Demonstration}

\section{Evaluation}

The Medicare Alzheimer's Disease Demonstration Evaluation (MADDE) was a randomized controlled evaluation of a combined case management and Medicare-reimbursed home care benefit service that was implemented in eight communities in the U.S. A detailed description of MADDE is provided in a supplemental issue of Health Services Research [36]. Briefly, to be eligible for MADDE, care recipients (a) had a physician-certified diagnosis of an irreversible dementia, (b) were enrolled or eligible for Parts A and B of Medicare, (c) had service needs, and (d) resided at home at baseline in one of the eight MADDE catchment areas. After 60 days in a $\mathrm{NH}$, MADDE service benefits were terminated. Nursing home admissions for less than 60 days that resulted in community discharge were recorded in MADDE but were not counted as "permanent" institutionalization episodes [37]. The caregiver was defined as the relative who provided the most help to the person with dementia. The baseline interview was in-person and biannual follow-up interviews were conducted via telephone over a three-year period. Interviews were administered up to 12 months following NHA. This study received Institutional Review Board exempt approval from the University of Minnesota Human Subjects Committee (IRB\# 0611E96989).

\section{Sample}

The baseline sample of MADDE included 5,831 caregivers and care recipients with dementia. Over $40 \%$ (43.9\%) of the persons with dementia were institutionalized during the three-year follow-up period. MADDE collected data on 1,610 caregivers six months after NHA (the six-month post-placement panel) and 1,116 caregivers 12 months following $\mathrm{NH}$ entry (the 12-month post-placement panel). The pre-placement interview was the last interview conducted prior to NHA. Baseline and outcomes data are presented in Table 1 for the 6-and 12-month post-placement panels.

\section{Measures}

\section{Outcomes}

The outcome variables were caregiver depressive symptoms, measured with the 15-item Geriatric Depression Scale (GDS) [38] and caregiver burden, measured with a 7 -item short form of the Zarit Burden Interview (ZBI) [39]. Based on prior sensitivity and specificity analyses on the 15-item version of the GDS $[40,41]$, a score of greater than or equal to six on the GDS was used to identify dementia caregivers suffering from clinically significant depression.

A clinically established cut-off for burden is less clear. For these reasons, we calculated a receiver operating characteristic (ROC) curve using the full baseline sample of MADDE $(N=5,831)$ to develop a potential cut-off score at which sensitivity and specificity (or the true negative rate) for identifying the clinically established cut-off for depression described above were optimized [31]. A cut-off score of 13.50 on the ZBI (range $=0.00$ to 28.00) was found to simultaneously maximize the sensitivity (correctly identifying $77 \%$ of the cases with depression) and specificity (identifying $71 \%$ who do not have depression) of the GDS. The area under the ROC curve was a high proportion of the overall space (.814) [42]. In subsequent analyses caregivers who reported a ZBI score of 13.00 or higher (as non-integer summed scores are not possible on the ZBI) were considered to have a clinically significant burden. 
Table 1 Descriptive Information, 6-month $(N=1,610)$ and 12-month $(1,116)$ Post-Placement Cohorts

\begin{tabular}{|c|c|c|c|c|c|c|}
\hline & \multicolumn{3}{|c|}{ 6-Month Post-Placement Cohort } & \multicolumn{3}{|c|}{ 12-Month Post-Placement Cohort } \\
\hline & $M / \%$ & $S D$ & Range & $M / \%$ & $S D$ & Range \\
\hline \multicolumn{7}{|l|}{ Context of Care } \\
\hline \multicolumn{7}{|l|}{ Site } \\
\hline Florida & $8.9 \%$ & & & $7.6 \%$ & & \\
\hline Illinois & $15.9 \%$ & & & $16.8 \%$ & & \\
\hline Minnesota & $21.9 \%$ & & & $22.0 \%$ & & \\
\hline New York & $13.2 \%$ & & & $14.4 \%$ & & \\
\hline Ohio & $14.7 \%$ & & & $16.2 \%$ & & \\
\hline Oregon & $9.6 \%$ & & & $8.4 \%$ & & \\
\hline Tennessee & $9.6 \%$ & & & $8.3 \%$ & & \\
\hline West Virginia & $6.1 \%$ & & & $6.2 \%$ & & \\
\hline CR is female & $59.3 \%$ & & & $63.7 \%$ & & \\
\hline CR is Caucasian & $92.0 \%$ & & & $92.2 \%$ & & \\
\hline CR age (years) & 71.47 & 7.62 & 30.63 to 102.10 & 78.83 & 7.41 & 47.03 to 97.06 \\
\hline CR is Medicaid eligible & $50.3 \%$ & & & $55.1 \%$ & & \\
\hline CR lives with $C G$ & $73.7 \%$ & & & $72.5 \%$ & & \\
\hline Treatment & $51.0 \%$ & & & $52.2 \%$ & & \\
\hline \multicolumn{7}{|l|}{ Kin Relationship } \\
\hline Wife & $33.4 \%$ & & & $29.0 \%$ & & \\
\hline Husband & $17.8 \%$ & & & $19.1 \%$ & & \\
\hline Daughter & $26.6 \%$ & & & $29.1 \%$ & & \\
\hline Other & $22.2 \%$ & & & $22.8 \%$ & & \\
\hline CG age (years) & 63.56 & 14.42 & 23.00 to 100.00 & 63.01 & 14.31 & 25.00 to 100.00 \\
\hline CG income ( $1=$ under $\$ 4,999 ; 11=\$ 50,000$ and above) & 5.81 & 2.91 & 1.00 to 11.00 & 5.90 & 2.91 & 1.00 to 11.00 \\
\hline CG is employed & $33.1 \%$ & & & $33.8 \%$ & & \\
\hline CG education ( 1 = elementary school; 6 = post-graduate) & 3.54 & 1.33 & 0.00 to 6.00 & 3.53 & 1.33 & 0.00 to 6.00 \\
\hline Duration of care at baseline (in months) & 44.21 & 38.53 & 0.00 to 360.00 & 43.98 & 39.09 & 0.00 to 360.00 \\
\hline Time to NHA from pre-placement (days) & 113.86 & 69.80 & 0.00 to 372.00 & 99.98 & 50.31 & 0.00 to 372.00 \\
\hline
\end{tabular}

Dementia Severity

MMSE at baseline

(2)

$8.9 \%$

$13.2 \%$

$9.6 \%$

$59.3 \%$

$92.0 \%$
$7.6 \%$
$16.8 \%$
$22.0 \%$
$14.4 \%$
$16.2 \%$
$8.4 \%$
$8.3 \%$
$6.2 \%$
$63.7 \%$

$92.2 \%$

$55.1 \%$

$72.5 \%$

$52.2 \%$

$29.0 \%$

$29.1 \%$

$26.6 \%$

(1) 


\section{Table 1: Descriptive Information, 6-month $(\mathrm{N}=1,610)$ and 12-month $(1,116)$ Post-Placement Cohorts (Continued)}

Functional Impairment

\begin{tabular}{|c|c|c|c|c|c|c|}
\hline Pre-placement ADLs & 4.34 & 2.55 & 0.00 to 10.00 & 4.26 & 2.48 & 0.00 to 10.00 \\
\hline Pre-placement IADLs & 7.13 & 1.20 & 0.00 to 8.00 & 7.10 & 1.20 & 1.00 to 8.00 \\
\hline Pre-placement caregiving hours (typical week) & 74.67 & 61.43 & 0.00 to 988.00 & 74.66 & 68.03 & 0.00 to 988.00 \\
\hline Pre-placement unmet needs & 2.92 & 4.31 & 0.00 to 18.00 & 3.02 & 4.36 & 0.00 to 18.00 \\
\hline \multicolumn{7}{|l|}{ ources } \\
\hline Pre-placement chore service use (times) & 29.76 & 98.08 & 0.00 to 1300.00 & 30.44 & 107.52 & 0.00 to 1300.00 \\
\hline Pre-placement personal care use (times) & 67.56 & 193.55 & 0.00 to 1456.00 & 77.26 & 210.83 & 00.00 to 1456.00 \\
\hline Pre-placement adult day service use (days) & 19.74 & 37.06 & 0.00 to 120.00 & 20.74 & 38.00 & 0.00 to 120.00 \\
\hline Pre-placement overnight hospital use (times) & 2.05 & 7.97 & 0.00 to 120.00 & 2.23 & 9.18 & 0.00 to 120.00 \\
\hline Pre-placement secondary caregiving hours (typical week) & 6.42 & 20.97 & 0.00 to 168.00 & 7.73 & 23.42 & 0.00 to 168.00 \\
\hline CG pre-placement self-reported health ( $1=$ excellent; $4=$ poor $)$ & 2.05 & .83 & 1.00 to 4.00 & 2.05 & .82 & 1.00 to 4.00 \\
\hline CG pre-placement ADLs & .24 & .69 & 0.00 to 5.00 & .22 & .63 & 0.00 to 5.00 \\
\hline CG pre-placement IADLs & .78 & 1.51 & 0.00 to 8.00 & .74 & 1.48 & 0.00 to 8.00 \\
\hline
\end{tabular}

Outcomes

\begin{tabular}{|c|c|c|}
\hline Pre-placement: Clinically significant burden ${ }^{a}$ & $52.9 \%$ & $52.9 \%$ \\
\hline 6-month post-placement: Clinically significant burden & $28.3 \%$ & $21.8 \%$ \\
\hline 12-month post-placement: Clinically significant burden & - & $16.7 \%$ \\
\hline Pre-placement: Clinically significant depression ${ }^{\text {b }}$ & $35.8 \%$ & $36.2 \%$ \\
\hline 6-month post-placement: Clinically significant depression & $31.1 \%$ & $25.3 \%$ \\
\hline 12-month post-placement: Clinically significant depression & - & $27.2 \%$ \\
\hline Persistent burden ${ }^{c}$ & $22.1 \%$ & $9.1 \%$ \\
\hline Persistent depression ${ }^{c}$ & $20.9 \%$ & $12.4 \%$ \\
\hline
\end{tabular}

NOTE: $M=$ mean; $S D=$ standard deviation; $C R=$ care recipient; $C G$ = caregiver; $N H A=$ nursing home admission; $A D L=$ activities of daily living; IADLs = instrumental activities of daily living; MMSE = Mini-Mental State Examination

${ }^{a}$ Those caregivers who indicated a Zarit Burden Inventory score of 13.00 or higher

${ }^{b}$ Those caregivers who reported a score of greater than or equal to six on the Geriatric Depression Scale

${ }^{\mathrm{c} C a r e g i v e r s ~ w h o ~ r e m a i n e d ~ i n ~ t h e ~ c l i n i c a l l y ~ h i g h ~ b u r d e n ~ a n d ~ d e p r e s s i o n ~ c a t e g o r i e s ~ p r i o r ~ t o ~ a n d ~ i n ~ t h e ~ 6-~ a n d ~ 12-m o n t h ~ i n t e r v a l s ~ f o l l o w i n g ~ p l a c e m e n t ~}$ 
A second objective of the current study was to identify predictors of persistently high depression or burden following the institutionalization transition. Persistent burden and persistent depression were operationalized as remaining at or above the clinical significance cut-points of burden and depression at the pre- and post-placement assessment intervals.

\section{Dementia severity}

Case managers administered the Mini-Mental State Examination (MMSE) [43] to care recipients at baseline to measure cognitive status. Frequency of care recipient behavior problems was assessed with the Memory and Behavior Problems Checklist, completed by caregivers at pre-placement [44].

\section{Functional impairment}

Measures of care recipients' pre-placement functional status included dependence in activity of daily living tasks (ADLs) [45] and instrumental activity of daily living tasks (IADLs) [46]. After caregivers reported whether care recipients needed no help, some help, or maximum help to perform each ADL or IADL, caregivers then indicated whether the care recipient was receiving enough help for that particular ADL or IADL (yes $=1$; no $=0)$. These unmet need items for each ADL or IADL task was then summed at pre-placement [47]. The number of hours caregivers typically spent providing assistance to care recipients was also included at pre-placement (primary informal caregiving hours).

\section{Resources}

Three community-based services (chore, personal care, and adult day care) and overnight hospital use for the care recipient were reported by caregivers at pre-placement. Secondary caregiving hours were measured at pre-placement by asking respondents how many hours they typically received help from other family members or friends in providing assistance to the care recipient (secondary caregiving hours). Other resource variables considered at pre-placement included caregivers' self-reported health status and caregivers' own functional dependency as measured by five ADLs and eight IADLs.

\section{Analysis \\ Objective 1: Description of clinically significant burden and depression across NHA}

The first analysis examined changes in clinically significant burden and depression at the pre- and post-placement intervals. Chi-square analyses were conducted to determine whether there were statistically significant changes $(P<.05)$ in the percentage of caregivers who reported clinically significant burden at pre-placement compared to caregivers at the 6-month and 12-month post-placement interviews. A parallel set of chi-square analyses were conducted to examine changes in clinically significant depression.

\section{Objective 2: Predicting persistent burden and depression across NHA}

The second objective was to identify those pre-placement variables that accounted for persistent burden or depressive symptoms in the 6- and 12-month post-placement panels. We used separate logistic regression models to identify variables that were predictive of persistent burden or depression up to 6 and 12 months after NHA using all of the variables described above as predictors. In order to ensure a relevant comparison, the reference category consisted of caregivers who scored below the clinical threshold of burden or depression at pre-and post-placement. All background/contextual, dementia severity, functional impairment, and resource indicators were included as independent variables. Since conceptual models of dementia caregiving often position emotional stressors as predictors of global outcomes such as depression [35], pre-placement burden was included as an additional predictor of persistent depressive symptoms in the logistic regression models.

\section{Results}

Objective 1: Description of clinically significant burden and depressive symptoms across the placement transition The percentage of caregivers who reported clinically significant burden decreased from pre-placement to the sixmonth post-placement follow-up (pre-placement burden $=52.9 \%$, six-month post-placement burden $=28.3 \%$; $d f=$ $\left.1 ; \chi^{2}=162.30 ; P<.001\right)$. Although statistically significant, the reduction in clinically significant depressive symptoms up to six months after NHA was less pronounced (pre-placement depressive symptoms $=35.8 \%$, six-month post-placement depressive symptoms $=31.1 \%$; $d f=1$; $\left.\chi^{2}=315.65 ; P<.001\right)$. Similar findings occurred in the 12 -month post-placement panel. The percentage of caregivers who indicated clinically significant burden dropped considerably from pre-placement to the 12-month postplacement interview (pre-placement burden $=52.9 \%$, 12 -month post-placement burden $=16.7 \% ; d f=1 ; \chi^{2}=$ 92.18; $P<.001)$. Significant, although smaller, reductions also occurred in reports of clinically significant depression up to one year after NHA (pre-placement depressive symptoms $=36.2 \%$; 12 -month post-placement depressive symptoms $\left.=27.2 \% ; d f=1 ; \chi^{2}=191.66 ; P<.001\right)$.

\section{Objective 2: Predicting persistent burden and depression across NHA \\ Persistent burden}

Table 2 provides the results of the logistic regression models predicting persistent burden up to 6 and 12 months post-placement, respectively. The models 
Table 2 Predictors of persistent burden in the 6-month and 12-month Post-Placement Panels $(\mathbf{N}=1,015 ; 560$ respectively)a

\begin{tabular}{|c|c|c|c|c|c|c|}
\hline \multirow[b]{2}{*}{ Variables } & \multicolumn{3}{|c|}{ 6-Month Post-Placement Panel } & \multicolumn{3}{|c|}{ 12-Month Post-Placement Panel } \\
\hline & $B$ & $S E$ & $O R$ & $B$ & $S E$ & $O R$ \\
\hline \multicolumn{7}{|l|}{ Context of Care } \\
\hline \multicolumn{7}{|l|}{ Site } \\
\hline Florida & $1.85^{* * *}$ & .44 & 6.36 & $2.05^{* * *}$ & .81 & 7.78 \\
\hline Illinois & -.12 & .40 & .77 & -.32 & .70 & .73 \\
\hline Minnesota & .00 & .39 & 1.00 & -.31 & .68 & .73 \\
\hline New York & .57 & .42 & 1.76 & -1.62 & 1.01 & .20 \\
\hline Ohio & .51 & .39 & 1.66 & .75 & .66 & 2.11 \\
\hline Oregon & $1.11^{*}$ & .44 & 3.02 & $1.87^{*}$ & .78 & 6.51 \\
\hline Tennessee & .32 & .43 & 1.38 & .10 & .80 & 1.10 \\
\hline \multicolumn{7}{|l|}{ West Virginia (reference) } \\
\hline$C R$ is female & .26 & .37 & 1.30 & -.64 & .67 & .53 \\
\hline CR is Caucasian & $.65^{*}$ & .33 & 1.92 & $2.28^{* *}$ & .75 & 9.77 \\
\hline CR age & -.01 & .01 & .99 & -.01 & .03 & .99 \\
\hline CR is Medicaid eligible & .19 & .19 & 1.21 & .50 & .39 & 1.65 \\
\hline CR lives with CG & .23 & .27 & 1.26 & .14 & .62 & 1.15 \\
\hline Treatment & -.10 & .18 & .91 & -.42 & .36 & .66 \\
\hline \multicolumn{7}{|l|}{ Kin relationship } \\
\hline Wife & $2.18^{* * *}$ & .49 & 8.84 & $3.37^{* *}$ & 1.01 & 29.16 \\
\hline Husband & .77 & .43 & 2.15 & $2.33^{*}$ & .96 & 10.26 \\
\hline Daughter & $1.01^{* * *}$ & .28 & 2.75 & $1.36^{*}$ & .57 & 3.89 \\
\hline \multicolumn{7}{|l|}{ Other (reference) } \\
\hline CG age & -.01 & .01 & .99 & -.03 & .03 & .97 \\
\hline CG income & .00 & .04 & 1.00 & .09 & .08 & 1.10 \\
\hline CG is employed & $.59^{*}$ & .24 & 1.81 & $1.13^{*}$ & .46 & 3.10 \\
\hline CG education & .11 & .08 & 1.12 & $-.29^{*}$ & .15 & .75 \\
\hline Duration of care & $.01^{* *}$ & .00 & 1.01 & $.01^{* *}$ & .00 & 1.01 \\
\hline
\end{tabular}

Time to NHA from pre-placement

0 to 61 days (reference)

61.01 to 105 days

$-.13-26$

105.01 to 151 days

$-.01-.25$

.87

.99

-.53
-.63
-.22

.49

.59

.19

.25

1.21

.50

.53

Over 151 days

Dementia severity

MMSE at baseline

.01

.01

1.01

.05

.02 
Table 2: Predictors of persistent burden in the 6-month and 12-month Post-Placement Panels $(\mathrm{N}=1,015 ; 560$ respectively)a (Continued)

Pre-placement behavior problems

Functional impairment

Pre-placement ADLs

Pre-placement IADLs

Pre-placement caregiving Hours

0 to 20 hours (reference)

20.01 to 70 hours

70.01 hours to 118 hours

Over 118 hours

Pre-placement unmet needs

Resources

Any pre-placement chore service use

Any pre-placement personal care use

Any pre-placement adult day service use

Any pre-placement overnight hospital use

Any pre-placement secondary caregiving hours

CG pre-placement self-reported health

CG pre-placement ADLs

CG pre-placement IADLs
$-.04$

.05

\section{$1.20^{* * *}$ \\ $1.58^{* * *}$ \\ $1.57^{* * *}$}

$.13^{* * *}$
.05

.10

.27

.30

.31

.02

.02

-

1.14

$24^{* * *}$

.05

1.28

Caregivers who did not indicate clinically significant burden at pre-placement or post-placement intervals was the reference category $(n=659$ in 6 -month postplacement panel; $n=459$ in the 12-month post-placement panel)

NOTE: $C R$ = care recipient; $C G$ = caregiver; NHA = nursing home admission; $A D L=$ activities of daily living; IADLs = instrumental activities of daily living; $M M S E=$ Mini-Mental State Examination

accounted for $49 \%$ of the variance in the 6 -month postplacement panel and $63 \%$ of the variance in the 12 month post-placement panel (Nagelkerke $R^{2}=.49$ and .63 , respectively). Several variables were significantly related $(P<.05)$ to persistent burden across the postplacement panels, including site (caregivers from Florida or Oregon), race/ethnicity (Caucasian), employment, longer duration of care, more time spent in at-home care, greater unmet need, and more frequent behavior problems. With each point increase in subjective health impairment, caregivers were 2.36 and 3.01 times more likely to report persistent burden in the 6- and 12 month post-placement panels, respectively. Gender and kin relationship in particular appeared to have a strong influence on persistent burden; when compared to other caregivers, women reported more persistent burden than men. Wives were over eight times more likely to experience persistent burden in the 6 -month postplacement panel $(O R=8.84)$ and even more likely to do so in the 12-month post-placement panel $(O R=29.16)$. Daughters also appeared more than twice as likely to indicate persistent burden when compared to other caregivers in the 6-month $(O R=2.75)$ and 12 -month post-placement panels $(O R=3.89)$.

\section{Persistent depression}

Table 3 presents the results of the logistic regression models predicting persistently high symptoms of depression in the 6- and 12-month post-placement panels. 
Table 3 Predictors of persistent depression in the 6-month and 12-month Post-Placement Panels $(\mathbf{N}=1,208 ; 710$ respectively)a

\begin{tabular}{|c|c|c|c|c|c|c|}
\hline \multirow[b]{2}{*}{ Variables } & \multicolumn{3}{|c|}{$\begin{array}{c}\text { 6-Month Post-Placement } \\
\text { Panel }\end{array}$} & \multicolumn{3}{|c|}{$\begin{array}{c}\text { 12-Month Post-Placement } \\
\text { Panel }\end{array}$} \\
\hline & $B$ & $S E$ & OR & $B$ & $S E$ & $O R$ \\
\hline \multicolumn{7}{|l|}{ Context of Care } \\
\hline \multicolumn{7}{|l|}{ Site } \\
\hline Florida & .59 & .53 & 1.80 & -.70 & .83 & .50 \\
\hline Illinois & -.46 & .50 & .63 & -1.21 & .78 & .30 \\
\hline Minnesota & -.90 & .49 & .41 & $-2.15^{* *}$ & .79 & .12 \\
\hline New York & $-1.11^{*}$ & .53 & .33 & $-2.50^{* *}$ & .89 & .08 \\
\hline Ohio & -.32 & .50 & .73 & -1.43 & .77 & .24 \\
\hline Oregon & -.17 & .55 & .84 & -.51 & .94 & .60 \\
\hline Tennessee & -.20 & .53 & .82 & -.85 & .81 & .43 \\
\hline \multicolumn{7}{|l|}{ West Virginia (reference) } \\
\hline$C R$ is female & $-.94^{*}$ & .41 & .39 & -1.11 & .70 & .33 \\
\hline CR is Caucasian & .24 & .39 & 1.27 & .03 & .74 & 1.03 \\
\hline CR age & -.03 & .02 & .97 & -.05 & .03 & .95 \\
\hline CR is Medicaid eligible & .24 & .21 & 1.27 & .29 & .36 & 1.34 \\
\hline$C R$ lives with $C G$ & .19 & .31 & 1.21 & .35 & .59 & 1.41 \\
\hline Treatment & .12 & .20 & 1.13 & .01 & .34 & 1.01 \\
\hline \multicolumn{7}{|l|}{ Kin relationship } \\
\hline Wife & .51 & .51 & 1.66 & 1.18 & .92 & 3.26 \\
\hline Husband & $1.58^{* *}$ & .49 & 4.87 & $1.77^{*}$ & .84 & 5.89 \\
\hline Daughter & .34 & .34 & 1.41 & 1.00 & .70 & 2.72 \\
\hline \multicolumn{7}{|l|}{ Other (reference) } \\
\hline CG age & .01 & .02 & 1.01 & .02 & .03 & 1.02 \\
\hline CG income & $-.08^{*}$ & .04 & .92 & -.07 & .07 & .94 \\
\hline CG is employed & .23 & .28 & 1.26 & -.24 & .45 & .59 \\
\hline CG education & -.08 & .08 & .92 & -.22 & .14 & .81 \\
\hline Duration of care & .00 & .00 & 1.00 & .01 & .00 & 1.01 \\
\hline
\end{tabular}

Time to NHA from pre-placement

0 to 63 days (reference)

63.01 to 99.98 days

99.99 to 140.75 days

Over 140.75 days

$\begin{array}{llllll}.08 & .28 & 1.08 & .64 & .49 & 1.89 \\ .22 & .27 & 1.24 & .78 & .45 & 2.19 \\ .26 & .31 & 1.30 & .69 & .48 & 1.99\end{array}$

Dementia severity 
Table 3: Predictors of persistent depression in the 6-month and 12-month Post-Placement Panels ( $N=1,208 ; 710$ respectively)a (Continued)

Pre-placement behavior problems

.03

1.01

.05

1.01

Functional impairment

Pre-placement ADLs

$\begin{array}{llllll}.01 & .06 & 1.02 & .02 & .09 & 1.02\end{array}$

Pre-placement IADLs

$\begin{array}{llllll}-.08 & .08 & .93 & -.14 & .24 & .87\end{array}$

Pre-placement caregiving hours

0 to 20 hours (reference)

20.01 to 70 hours

70.01 hours to 112 hours

Over 112 hours

Pre-placement unmet needs

(n)

Resources

\begin{tabular}{|c|c|c|c|c|c|c|}
\hline Any pre-placement chore service use & .35 & .22 & 1.42 & .32 & .37 & 1.37 \\
\hline Any pre-placement personal care use & -.06 & .24 & .94 & .28 & .40 & 1.32 \\
\hline Any pre-placement adult day service use & -.22 & .22 & .80 & -.34 & .37 & .72 \\
\hline Any pre-placement overnight hospital use & .36 & .26 & 1.43 & -.21 & .47 & .81 \\
\hline Pre-placement secondary caregiving hours (less than 1 hour per week is reference) & -.11 & .21 & .90 & $-.90^{* *}$ & .34 & .41 \\
\hline CG pre-placement self-reported health & $.74^{* * *}$ & .14 & 2.11 & $.87^{* * *}$ & .23 & 2.39 \\
\hline CG pre-placement ADLs & .26 & .18 & 1.29 & .34 & .27 & 1.41 \\
\hline CG pre-placement IADLs & .14 & .08 & 1.15 & $.34^{* *}$ & .13 & 1.40 \\
\hline Pre-placement burden & $.28^{* * *}$ & .02 & 1.32 & $.28^{* * *}$ & .04 & 1.32 \\
\hline
\end{tabular}

${ }^{a}$ Caregivers who did not indicate clinically significant depression at pre-placement or post-placement intervals was the reference category $(n=871$ in the 6 month post-placement panel; $n=572$ in the 12-month post-placement panel)

NOTE: $C R=$ care recipient; $C G=$ caregiver; $N H A=$ nursing home admission; $A D L=$ activities of daily living; IADLs = instrumental activities of daily living; MMSE = Mini-Mental State Examination

The post-placement models accounted for a considerable amount of variance in persistent depression in the 6-month (Nagelkerke $R^{2}=.64$ ) and 12-month (Nagelkerke $\left.R^{2}=.71\right)$ post-placement panels. Husbands were 4.87 times and 5.89 times more likely to indicate persistent depression than other caregivers in the 6- and 12month post-placement panels, respectively. Caregivers who reported a point increase in subjective health impairment were 2.11 and 2.39 times more likely to indicate persistent depression in the 6- and 12-month post-placement panels, respectively. In addition, caregivers in New York were less likely to indicate persistent depression in the 6-month and 12-month post-placement panels $(O R=.33 ; O R=.08$, respectively $)$.

\section{Discussion}

The proportion of caregivers who reported clinically significant levels of burden prior to placement was dramatically reduced 6 and 12 months following NHA. A similar change occurred in clinically significant depression following institutionalization, although the reduction was less pronounced. Nursing homes assume many of the challenging care tasks that informal caregivers had provided. Specifically, NHs play a strong 
"substitution" role as formal care providers (staff) assume the care responsibilities formerly provided by informal caregivers (family members) $[48,49]$. This may lead to considerable emotional and psychological relief for family members.

This is not to say that some family caregivers do not experience distress or challenges during NHA. While several sociodemographic and contextual characteristics predicted persistent, clinically significant burden across the 6- and 12-month post-placement panels, kin relationship emerged as a potent influence. Female caregivers, and wives in particular, appeared far more likely to experience persistent burden following institutionalization. Female caregivers generally are more involved in day-to-day hands-on care provision and may also have a more difficult time relinquishing this role to 24-hour $\mathrm{NH}$ care staff; for example, wives tend to indicate more emotional investment in their caregiving roles when compared to other caregivers and also provide more direct care than husbands at pre-placement. This may continue after institutionalization (for example, supervising the care tasks performed by $\mathrm{NH}$ staff, playing an advocacy role for the institutionalized husband to ensure proper care is delivered in the NH) $[2,12,31,32]$. Therefore, stress may not abate with NHA for female caregivers who are heavily engaged in the emotional and direct, day-to-day care challenges associated with assisting a relative with dementia. Caregivers who indicated more frequent behavior problems in their relatives, provided more hands-on care, reported unmet needs pertaining to functional dependence of care recipients, and struggled with health or functional impairments of their own were also more likely to experience burden following $\mathrm{NH}$ placement. It may be that care recipients with more severe functional or behavioral impairments are more difficult for $\mathrm{NH}$ staff to manage successfully, so much so that their families feel compelled to remain involved in the care of institutionalized relatives and to interact regularly with $\mathrm{NH}$ staff to ensure proper care is delivered $[10,11]$. Such involvement is likely difficult to maintain when caregivers suffer from their own health impairments, thus leading to elevated burden after NHA.

Husbands, on the other hand, were particularly susceptible to post-placement depression across the 6- and 12 -month panels. Husbands may have difficulty in adapting to and confronting the emotional loss of a partner and disruption to the role of husband in the context of institutional placement. Moreover, husbands may be less likely to have a reservoir of social support to rely on during NHA. These factors could lead to increased depressive symptomatology. We also found that caregivers with greater subjective health impairment and pre-placement burden were more likely to experience persistent depression across post-placement panels, which adds to the evidence suggesting that caregivers with physical or emotional challenges during athome care may have continued psychological difficulty with the $\mathrm{NH}$ transition. It is possible that caregivers with emotional distress and health impairments may have felt increased guilt when they had to relinquish athome care responsibilities due to these issues.

We have noted in our prior research that the provision of intensive, individualized consultation can help mitigate reports of burden or depressive symptoms among dementia caregivers [24]. It appears that the expanded case management model of MADDE did not exert a significant influence on caregivers' depressive symptomatology or burden during the $\mathrm{NH}$ transition. Consideration of the descriptive findings here as well as our prior clinical work reiterates what is currently bestpractice in dementia caregiving intervention: multicomponent psychosocial interventions that combine individualized consultation with family sessions and ongoing support often exert the greatest benefits in improving dementia caregiver outcomes, delaying NHA, or enhancing dementia caregivers' experiences across key transition points $[6,50]$. Alternatively, case management/referral models such as the MADDE approach tend to yield less consistent effects on such outcomes.

Although this analysis had at its disposal a large, multi-regional data set, there are several limitations that are important to consider. One is that there is no specific information about the type of care received in the $\mathrm{NH}$ by the care recipient, extent of family care provided to cognitively impaired care recipients following institutionalization, or post-placement measures of care recipients' dementia severity or functional status. In addition, MADDE data were collected in the early $1990 \mathrm{~s}$. Since then a number of developments have occurred in longterm care, such as market availability and the emergence of assisted living, which may influence families' placement decisions. Although the MADDE data set is large, it did not rely on probability sampling techniques. Since to our knowledge no "gold standard" clinical rating of burden currently exists [51], we had to rely on the GDS to establish the clinically significant cut-point for burden. The sample size is also largely Caucasian. While this is expected due to lower $\mathrm{NH}$ placement rates frequently reported by African-American and Latino caregivers [52], such disparity may still influence generalizability. As noted by Jacobson and colleagues [53], the construct of clinical significance is best operationalized as "recovered," "improved but not recovered," and "still dysfunctional." In order to improve clarity of our interpretation, we limited the outcome to those who "recovered" and those who were "still dysfunctional" per the Jacobson classification. Inclusion of the third category 
(improved but not recovered) may have offered a fuller picture as to how each of these three potential outcomes occurred across the NH transition.

Several site effects were also apparent [[31], p. 394]. A limitation of MADDE was the lack of regional data to explain why site variations occurred in outcomes such as burden or depressive symptoms. Issues ranging from culture, to varying methods of MADDE implementation, to staffing ratios may have accounted for site-level variation in key variables. Historical events (Hurricane Andrew occurred in Florida in 1992) may have also influenced dementia caregivers' reports of distress during MADDE. Overall, the variations across site suggest that future multi-regional caregiving studies (descriptive or intervention-focused) must incorporate site data to explain the manifestation of key outcomes.

As the nature of family involvement may shift with residential care placement, it is possible that measures of caregiver stress require modification to better capture dimensions pertinent to the $\mathrm{NH}$ environment following institutionalization. As we have emphasized in prior research $[24,31]$ future measures should approach NHA as a transitional event with a focus on pre-admission and post-placement factors. Key pre-admission variables could include how the decision to institutionalize came about, how helpful the $\mathrm{NH}$ was in facilitating the move, difficulty in finding an appropriate facility, and overall satisfaction with the institutionalization experience. During postplacement, greater attention to family caregivers' experiences with NHs such as family-staff interactions, types of family involvement, perceptions of collaboration with $\mathrm{NH}$ staff, and ratings of the philosophy of care (for example, family-centered emphasis) may improve measurement of the NH transition's influence on dementia caregivers.

\section{Conclusion}

The findings of these analyses have several implications for future research and practice. Perhaps the most striking result is the apparent effect of NHA on clinical reports of burden and depressive symptoms following institutionalization. Our results emphasize that placement itself may provide relief and reductions in negative outcomes for dementia caregivers, particularly burden (in which we found a more considerable decrease than in depressive symptoms). Is it possible to reconcile our results with the ongoing focus of federal, state, and local support services to prevent NHA and save taxpayerfinanced healthcare costs (for example, Medicaid in the U.S.), since this study shows that for many dementia caregivers placement may actually exert significant, clinical benefits? Perhaps the emphasis on preventing institutionalization is less appropriate than identifying the right time to make the placement decision or determining what types of support are optimal to reduce burden and depression during the period the person is cared for at home as well as during the NH transition [54]. More widespread implementation of effective psychosocial interventions to reduce caregiver burden and depression prior to the transition to $\mathrm{NH}$ placement can ameliorate the symptoms of burden and depression and increase the likelihood that a placement event is not premature, but instead occurs at an appropriate time. Nursing home admission should be viewed as a key transition faced in the course of dementia as opposed to a clinical endpoint.

While NHA may help to reduce overall burden and depressive symptoms in most caregivers, some may experience continued emotional and psychological distress well after institutionalization. The results of this study help to construct a profile of caregivers most atrisk for clinically high, persistent negative outcomes in the months after NHA. Wives, daughters, caregivers who have challenges meeting the needs of care recipients, and caregivers who have difficulty with their own health needs appear particularly susceptible to clinically persistent burden in the months immediately following NHA. Husbands and caregivers who experience health impairments and emotional stressors of their own prior to institutionalization appear most likely to suffer from clinically significant depression throughout the NH transition. Our findings can serve as an initial step in developing a screening process to identify families at-risk for burden or depression immediately prior and subsequent to institutionalization. Such families might benefit from psychosocial interventions (such as those provided by $\mathrm{NH}$ social workers or family nurse practitioners) during NHA to ease the transition and alleviate adverse outcomes following institutionalization. For example, using a transition "coach" during the pre-admission phase, the entry process, and in the months following admission could provide education regarding the $\mathrm{NH}$ environment and care policies, management of emotions and stress that may occur during the entry process (for example, guilt or grief), validation of families' decisions, and advocacy in facilitating interactions between $\mathrm{NH}$ care staff and administration. Such an approach may help families navigate the $\mathrm{NH}$ transition, and the development and testing of this or similar interventions could serve as a focus for future evaluation.

\section{Abbreviations}

ADLs: activities of daily living; $d f$ : degrees of freedom; GDS: Geriatric Depression Scale; IADLs: instrumental activities of daily living; MADDE: Medicare Alzheimer's Disease Demonstration Evaluation; MMSE: Mini-Mental Status Examination; NH: nursing home; NHA: nursing home admission; ROC: receiver operating characteristic; U.S.: United States; ZBI: Zarit Burden Inventory

\section{Acknowledgements}

Funding sources and related paper presentations: This research was supported by grant R21 AG025625 from the National Institute on Aging/ 
National Institutes of Health. A version of this paper was presented at the 2008 Gerontological Society of America Meeting, National Harbor, Maryland, U.S.

\section{Author details}

${ }^{1}$ School of Nursing, Center on Aging, University of Minnesota, Minneapolis, MN, USA. ${ }^{2}$ Department of Psychiatry, New York University Langone Medical Center, New York, NY, USA. ${ }^{3}$ School of Nursing, Emory University, Atlanta, GA, USA. ${ }^{4}$ Department of Social and Behavioral Science, University of California, San Francisco, CA, USA.

\section{Authors' contributions}

JEG conceptualized the current study, conducted the analyses, and wrote all sections of the manuscript. MSM assisted JEG in conceptualizing the current study, assisted JEG in interpreting the analysis, and reviewed and revised all sections of the manuscript. $\mathrm{KH}$ reviewed all sections of the manuscript and provided feedback on the analytic plan. RN provided feedback on the analytic plan, assisted JEG in interpreting the results, and reviewed and revised the manuscript. All authors read and approved the final manuscript.

\section{Competing interests}

The authors declare that they have no competing interests.

Received: 10 November 2010 Accepted: 17 December 2010

Published: 17 December 2010

\section{References}

1. Wolff $\lrcorner$, Kasper JD: Caregivers of frail elders: updating a national profile. Gerontologist 2006, 46:344-356.

2. Pinquart $M$, Sorensen S: Associations of stressors and uplifts of caregiving with caregiver burden and depressive mood: a meta-analysis. J Gerontol B Psychol Sci Soc Sci 2003, 58:P112-128.

3. Vitaliano PP, Zhang J, Scanlan JM: Is caregiving hazardous to one's physical health? A meta-analysis. Psychol Bull 2003, 129:946-972.

4. Logsdon RG: Dementia: psychosocial interventions for family caregivers. Lancet 2008, 372:182-183.

5. Mason A, Weatherly H, Spilsbury K, Golder S, Arksey H, Adamson J, Drummond $M$ : The effectiveness and cost-effectiveness of respite for caregivers of frail older people. J Am Geriatr Soc 2007, 55:290-299.

6. Mittelman MS, Haley WE, Clay OJ, Roth DL: Improving caregiver well-being delays nursing home placement of patients with Alzheimer's disease. Neurology 2006, 67:1592-1599.

7. Winblad B, Wimo A, Almkvist O: Outcome measures in Alzheimer's disease: Do they go far enough? Dement Geriatr Cogn Disord 2000 11(supp 1):3-10

8. Schulz R, O'Brien A, Czaja S, Ory M, Norris R, Martire LM, Belle SH, Burgio L, Gitlin L, Coon D, Burns R, Gallagher-Thompson D, Stevens A: Dementia caregiver intervention research: i6n search of clinical significance. The Gerontologist 2002, 42:589-602.

9. Alzheimer's Association: 2009 Alzheimer's Disease Fact and Figures Chicago, IL: The Alzheimer's Association; 2009.

10. Bowers BJ: Family perceptions of care in a nursing home. Gerontologist 1988, 28:361-368.

11. Maas ML, Reed D, Park M, Specht JP, Schutte D, Kelley LS, Swanson EA, Tripp-Reimer T, Buckwalter KC: Outcomes of family involvement in care intervention for caregivers of individuals with dementia. Nurs Res 2004, 53:76-86.

12. Gaugler JE: Family involvement in residential long-term care: a synthesis and critical review. Aging Ment Health 2005, 9:105-118.

13. Gaugler JE, Yu F, Krichbaum K, Wyman JF: Predictors of nursing home admission for persons with dementia. Med Care 2009, 47:191-198.

14. Yamamoto MN, Aneshensel CS, Levy-Storms L: Patterns of family visiting with institutionalized elders: the case of dementia. J Gerontol B Psychol Sci Soc Sci 2002, 57:S234-S246.

15. Bauer M, Nay R: Family and staff partnerships in long-term care. A review of the literature. J Gerontol Nurs 2003, 29:46-53.

16. Boise $L$, White $D$ : The family's role in person-centered care: practice considerations. J Psychosoc Nurs Ment Health Serv 2004, 42:12-20.

17. Port CL, Zimmerman S, Williams CS, Dobbs D, Preisser JS, Williams SW: Families filling the gap: comparing family involvement for assisted living and nursing home residents with dementia. Gerontologist 2005, 45:87-95.
18. Port CL: Informal caregiver involvement and illness detection among cognitively impaired nursing home residents. J Gerontol A Biol Sci Med Sci 2006, 61:M970-974.

19. Gaugler JE, Pot AM, Zarit SH: Long-term adaptation to institutionalization in dementia caregivers. Gerontologist 2007, 47:730-740.

20. Matsuda O, Hasebe N, Ikehara K, Futatsuya M, Akahane N: Longitudinal study of the mental health of caregivers caring for elderly patients with dementia: effect of institutional placement on mental health. Psychiatry Clin Neurosci 1997, 51:289-293.

21. Schulz R, Belle SH, Czaja SJ, McGinnis KA, Stevens A, Zhang S: Long-term care placement of dementia patients and caregiver health and wellbeing. JAMA 2004, 292:961-967

22. Whitlatch CJ, Schur D, Noelker LS, Ejaz FK, Looman WJ: The stress process of family caregiving in institutional settings. Gerontologist 2001, 41:462-473.

23. Zarit SH, Whitlatch CJ: Institutional placement: Phases of transition. Gerontologist 1992, 32:665-672.

24. Gaugler JE, Roth DL, Haley WE, Mittelman MS: Can counseling and support reduce burden and depressive symptoms in caregivers of people with Alzheimer's disease during the transition to institutionalization? Results from the New York University caregiver intervention study. J Am Geriatr Soc 2008, 56:421-428.

25. Gold DP, Reis MF, Markiewicz D, Andres D: When home care giving ends: A longitudinal study of outcomes for caregivers of relatives with dementia. J Am Geriatr Soc 1995, 43:10-16.

26. Grasel E: When home care ends-changes in the physical health of informal caregivers caring for dementia patients: a longitudinal study. J Am Geriatr Soc 2002, 50:843-849.

27. Mausbach BT, Aschbacher K, Patterson TL, von Kanel R, Dimsdale JE, Mills PJ, Ancoli-Israel S, Grant I: Effects of placement and bereavement on psychological well-being and cardiovascular risk in Alzheimer's caregivers: a longitudinal analysis. J Psychosom Res 2007, 62:439-445.

28. Almberg B, Grafstrom M, Krichbaum K, Winblad B: The interplay of institution and family caregiving: Relations between patient hassles, nursing home hassles and caregivers' burnout. Int J Geriat Psychiatry 2000, 15:931-939.

29. Majerovitz SD: Predictors of burden and depression among nursing home family caregivers. Aging Ment Health 2007, 11:323-329.

30. Gaugler JE, Leitsch SA, Zarit SH, Pearlin LI: Caregiver involvement following institutionalization: effects of preplacement stress. Res Aging 2000, 22:337-359.

31. Gaugler JE, Mittelman MS, Hepburn K, Newcomer R: Predictors of change in caregiver burden and depressive symptoms following nursing home admission. Psychol Aging 2009, 24:385-396.

32. Pillemer K, Suitor JJ, Henderson CR, Meador R, Schultz L, Robison J, Hegeman C: A cooperative communication intervention for nursing home staff and family members of residents. Gerontologist 2003, , 43 Special Issue II: 96-106.

33. Levesque L, Ducharme $F$, Lachance $L$ : Is there a difference between family caregiving of institutionalized elders with or without dementia? West $J$ Nurs Res 1999, 21:472-491.

34. Tornatore $J B$, Grant LA: Family caregiver satisfaction with the nursing home after placement of a relative with dementia. J Gerontol B Psychol Sci Soc Sci 2004, 59:S80-88.

35. Pearlin LI, Mullan JT, Semple SJ, Skaff MM: Caregiving and the stress process: An overview of concepts and their measures. Gerontologist 1990, 30:583-594.

36. Newcomer R, Yordi C, DuNah R, Fox P, Wilkinson A: Effects of the Medicare Alzheimer's Disease Demonstration on caregiver burden and depression. Health Serv Res 1999, 34:669-689.

37. Miller R, Newcomer R, Fox P: Effects of the Medicare Alzheimer's Disease Demonstration Evaluation on nursing home entry. Health Serv Res 1999, 34:691-714.

38. Sheikh J, Yesavage J: Geriatric Depression Scale: Recent evidence and development of a shorter version. Clin Gerontologist 1986, 5:165-173.

39. Zarit SH, Reever KE, Bach-Peterson J: Relatives of the impaired elderly: Correlates of feelings of burden. Gerontologist 1980, 20:649-655.

40. McDowell I, Newell C: Social health. Measuring health: A Guide to Rating Scales and Questionnaires. 2 edition. New York: Oxford University Press; 1996. 
41. Lyness JM, Noel TK, Cox C, King DA, Conwell Y, Caine ED: Screening for depression in elderly primary care patients. A comparison of the Center for Epidemiologic Studies-Depression Scale and the Geriatric Depression Scale. Arch Intern Med 1997, 157:449-454.

42. Simon S: Stats: ROC curve (online). [http://www.childrensmercy.org/stats/ ask/roc.asp], Accessed April 9, 2009.

43. Folstein MF, Folstein SE, McHugh PR: Mini-Mental State: A practical method for grading the cognitive state of patients for the clinician. J Psychiatr Res 1975, 12:189-198.

44. Zarit SH, Orr N, Zarit J: Understanding the stress of caregivers: planning an intervention. In Hidden Victims of Alzheimer's Disease: Families under Stress. Edited by: Zarit SH, Orr N, Zarit J. New York: NYU Press; 1985:69-86.

45. Katz S, Ford AB, Moskowitz RW, Jackson BA, Jaffe MW: Studies of illness in the aged. The Index of ADL: A standardized measure of biological and psychosocial function. JAMA 1963, 185:914-919.

46. Lawton MP, Brody EM: Assessment of older people: self-maintaining and instrumental activities of daily living. Gerontologist 1969, 9:179-186.

47. Gaugler JE, Kane RL, Kane RA, Newcomer R: Unmet care needs and key outcomes in dementia. J Am Geriatr Soc 2005, 53:2098-2105.

48. Greene V: Substitution between formally and informally provided care for the impaired elderly in the community. Medical Care 1983, 21:609-619.

49. Lyons KS, Zarit SH: Formal and informal support: the great divide. Int J Geriatr Psychiatry 1999, 14:183-196.

50. Brodaty H, Green A, Koschera A: Meta-analysis of psychosocial interventions for caregivers of people with dementia. J Am Geriatr SoC 2003, 51:657-664.

51. Higginson IJ, Gao W, Jackson D, Murray J, Harding R: Short-form Zarit Caregiver Burden Interviews were valid in advanced conditions. J Clin Epidemiol 2010, 63:535-542.

52. Yaffe K, Fox P, Newcomer R, Sands L, Lindquist K, Dane K, Covinsky KE: Patient and caregiver characteristics and nursing home placement in patients with dementia. JAMA 2002, 287:2090-2097.

53. Jacobson NS, Roberts LJ, Berns SB, McGlinchey JB: Methods for defining and determining the clinical significance of treatment effects: description, application, and alternatives. J Consult Clin Psychol 1999, 67:300-307.

54. McClendon MJ, Smyth KA, Neundorfer MM: Long-term-care placement and survival of persons with Alzheimer's disease. J Gerontol B Psychol SCl Soc Sci 2006, 61:P220-227.

\section{Pre-publication history}

The pre-publication history for this paper can be accessed here: http://www.biomedcentral.com/1741-7015/8/85/prepub

doi:10.1186/1741-7015-8-85

Cite this article as: Gaugler et al:: Clinically significant changes in

burden and depression among dementia caregivers following nursing home admission. BMC Medicine 2010 8:85.

\section{Submit your next manuscript to BioMed Central and take full advantage of:}

- Convenient online submission

- Thorough peer review

- No space constraints or color figure charges

- Immediate publication on acceptance

- Inclusion in PubMed, CAS, Scopus and Google Scholar

- Research which is freely available for redistribution

Submit your manuscript at www.biomedcentral.com/submit
C Biomed Central 